\title{
On-line measurement of mechanical, optical properties and roughness
}

\section{parameters}

\author{
H. Hartman*, A. Casajus* and U. Richter*
}

\begin{abstract}
On-line measurements become a central importance for the control of production line output. The target is to replace traditional single local destructive quality checks by a continuous survey of the product properties. Other traditionals like pyrometric temperature measurements suffer of well-known but non-soluble weakness points. New methods need the unambiguous correlation with the results of traditional testing to be representative for valid proof standards.EKO Stahl $\mathrm{GmbH}$ introduces several methods of on-line measurements focussed actually on temperature measurement means of FTIRSpectrometer, prediction of the mechanical properties of steel strips using the information of residual magnetisation after a magnetisation pulse and optical roughness measurements. The correlation between the results of the new methods and the classical proof processes has been established in a satisfactory manner.
\end{abstract}

Keywords On-line measurement. Temperature. Mechanical properties. Roughness.

\section{Medida on line de las propiedades mecánicas, ópticas y parámetros de rugosidad}

Resumen

\begin{abstract}
Las medidas on line van tomando una importancia central para el control de la calidad de la production. El objetivo es reemplazar las pruebas destructivas puntuales tradicionales por un control continuo de las características del producto. Otros métodos tradicionales, como la medida de la temperatura con pirómetros, adolecen de conocidos pero insolubles puntos débiles. Los nuevos métodos necesitan la correlacion inéquivoca con los résultados de los métodos corrientes clásicos para obtener la autoridad de un estándar de prueba. La EKO Stahl GmbH ha introducido varios métodos de médidas on line, actualmente concentrados en la medida de la temperatura con espectrómetro FTIR, predicción de las características mecánicas usando la informacion del magnetismó residual, a partir de un impulso magneticó inicial así como la medida optica de la rugosidad. La correlación entre los resultados de los nuevos métodos y los métodos clásicos ha quedado establecida de manera satisfactoria.
\end{abstract}

Palabras clave Medida on line. Temperatura. Características mecánicas. Rugosidad.

\section{INTRODUCTION}

The increasing demands of the customers to meet tighter quality tolerances and to assure homogeneous properties in use over the strip length lead to an rising volume of application of online measurement systems for control of process conditions and assure product quality by the producers of metallurgical semi products ${ }^{[1]}$.

When measuring the product properties apart from the traditional geometrical quality parameters, like thickness, width and flatness, a growing number of additional parameter can be mentioned, which more directly describes the processibility of the material. This concerns e.g. the control of the defect free surface, the measurement of the topological surface characteristics and also the prediction of the mechanical properties of the material ${ }^{[2-5]}$. In spite of the parallel development to calculate the product parameters by use of modelling the process and product properties the trend to the online measurement is sustainable.

In the last years the activities for measurement of the process parameters has been increased.

In accordance to the efforts to reduce the volume of product control exists the objective to

(*) Forschungs- und Qualitätszentrum Eisenhüttenstadt, Industriepark EKO, Str $ß$ e 20. D-15890 Eisenhüttenstadt, Germany. 
guaranty a stable reproducible production process by meeting a small-scattered process window and by this the demanded product quality.

Additionally to the continuous measurement of the forces and stresses, of the geometrical length and the speed the continuous measurement of both the process and product temperature is an important prerequisite to obtain the required product quality.

Since already a long time EKO Stahl GmbH is paying attention to the different problems of online measurement of technological parameters, which determine the product quality. In particular at the galvanizing line $\# 2$, that is specially dedicated to the production of sheets for internal and external application in the automotive industry a row of online measurement systems is introduced (Fig. 1). These are e.g. the measurement of the true strip temperature, the prediction of the mechanical properties of the material as well as the online roughness measurement.

\subsection{Measurement of the true strip temperature}

The measurement of the strip temperature in HDG is a not fully solved today recurrent problem, depending on products grade, production conditions and quality requirements. The accuracy of the tempearture pyrometers is influenced by the change of the surface conditions especially during processing of new steel grades with higher surface oxidation behaviour as well as by the reflexted fluxes. The unsufficient adaptation of the emission coefficient remains such a source of unpredictable measurement defects ${ }^{[6]}$.

There are different methods under investigation to avoid or at least to reduce these deviations in temperature measurement. To the most prospective methods belong the multispectral approach, by measuring several wavelength ${ }^{[7-9]}$ and the so called wedge measurement, that due to the multiple reflexion of the measurement beam results in an emissivity independed control.

The measurement of the true temperature of hot steel surfaces using the infrared radiation is a not finally solved problem.

Today the radiation properties of real surfaces, described by the emissivity factor are not sufficiently understood yet to get a general approach for real quantification of its value for the initialisation of pyrometers for correct measurement ${ }^{[10]}$.

Furthermore when heating the steel strip different heating sources inside the furnace

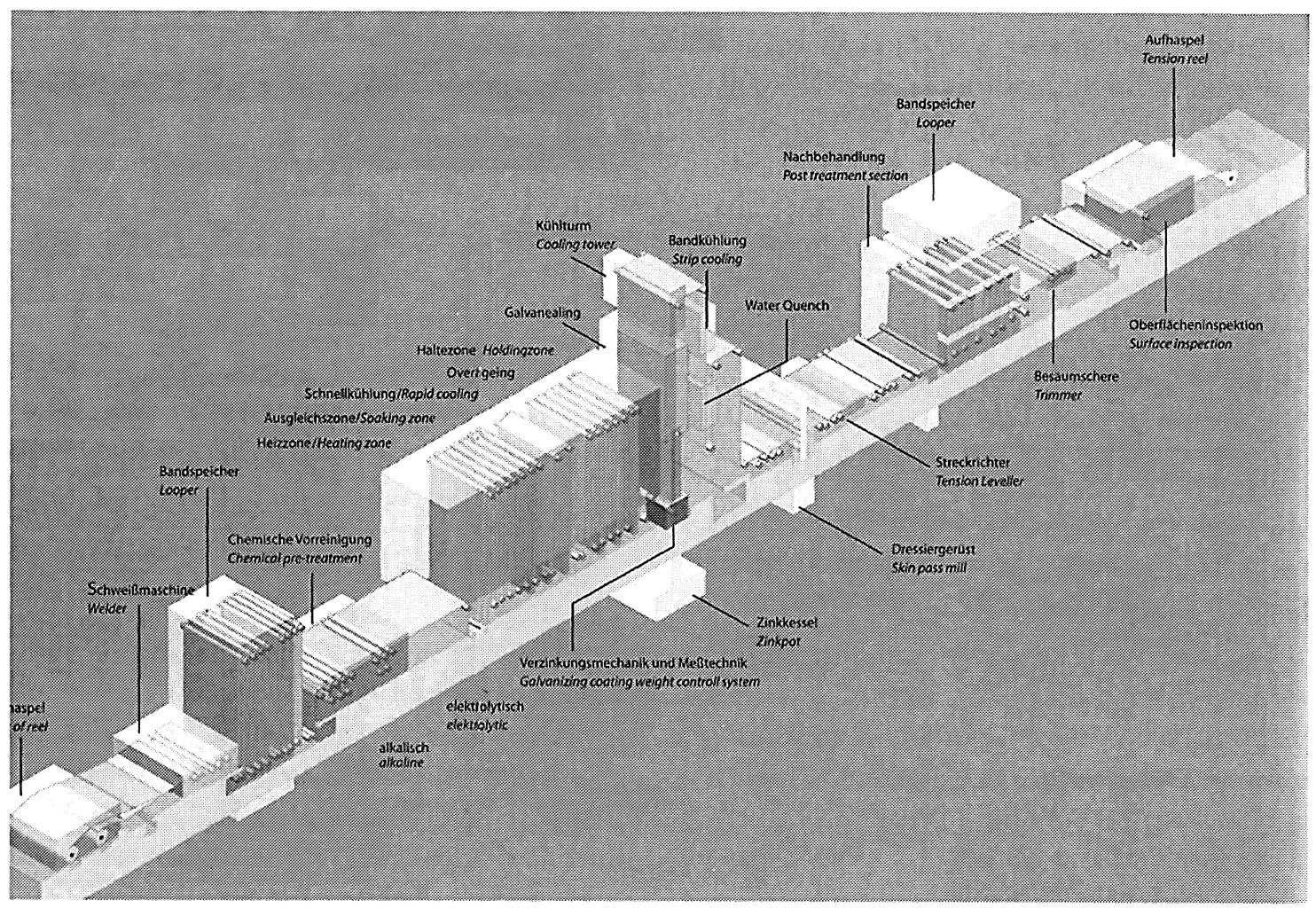

Figure 1. Overall view of a modern hot dip galvanising and galvanealing line.

Figura 1. Vista total de una línea moderna de galvanización y galvanizado por inmersión en caliente. 
contribute to the pyrometer signal by more or less multiple specular reflections on the moving strip reaching finally the input window of the measuring device.

Such the measured temperature signal is a superposition of the incident radiation of the running sheet, which properties are shared by an incompletely known emissivity factor and the temperature pattern of the ambient furnace walls.

To overcome this uncertainties in the temperature measurement a Fast Fourier Transform Infra Red Spectrometer (FFTIR) ${ }^{[11]}$ was already used by different groups ${ }^{[12}$ and 13$]$, finally adapted to record the total radiation profile of the moving heated strip and to calculate the true temperature afterwards ${ }^{[14]}$.

\subsection{Prediction of the mechanical properties of steel strips}

One of the most important quality characteristics of the galvanized strip are the mechanical properties. Normally the inspection is carried our by mechanical tensile test on samples cut out during the line stop at the end of the coils. Such only a local information about the mechanical properties of the coil is available which may not be characteristic over the entire length of the strip.

To overcome this disadvantage in the last years the continuous measurement of the mechanical properties is under investigation and there are first industrial applications application ${ }^{[15-18]}$.

Apart from the elimination of the time consuming and low informational mechanical testing of the strip quality the online prediction of the mechanical properties aims at the better process control and improvement of the productivity as well as on the acceleration of new product development.

Today only a few of online measurement systems exists to predict the mechanical properties inline the strip production process. These are the magnetic measuring systems 3MA (TKS / FHG Saarbrücken), HMS (SG AG/VAI/TU Hannover) and IMPOK (EMG) and the ultra sonic measuring device Sirius (Basse-Indre) ${ }^{[3 \text { and 19-21]. }}$

A benchmark between the different measuring systems showed that the IMPOK system, which is under application since 3 and 5 years on both the galvanizing line 1 and 2 at EKO Stahl is a promising development. This measurement devise is up to now the only industrial produced measurement system.

\subsection{Continuous roughness measurement}

The roughness of the strip surface is an imperative quality characteristic affecting both the formability of the material and the surface appearance of the coated part.

The evolution of the final micro profile is a complex process that occurs in all forming and processing stages of the strip by generation and superimposing of new and previous surface structures.

The multitude of different technical and technological parameters having an influence on the surface roughness profile demands for permanent control ${ }^{[22}$ and 23]. Normally this control is realised by off-line measurement on samples cut during the plant stop at the coil ends. The introduction of an online measurement system to improve the information about roughness deviation along the strip length is obviously ${ }^{[24]}$.

Currently the number of industrial online roughness measurement systems is restricted to R2000 (MESACON), WINDIS (DMO) and SORM3 (EMG) ${ }^{[25-27]}$.

In 2003 the optical roughness measuring system SORM3 + was installed at the galvanizing line 2 to measure the roughness parameter $\mathrm{Ra}$ and $\mathrm{RPc}$ along the strip length in up to 10 tracks over the strip width.

\section{MATERIALS AND EXPERIMENTAL PROCEDURE}

\subsection{Measurement of the true strip temperature}

The fundamental basic background for determination of the true steel strip temperature from the FTIR spectra was developed with help of a commercial FTIR spectrometer.

The FTIR measurements were carried out with a black body as thermal radiation source of exactly known temperature and a radiation spectrum under lab conditions to derivate the algorithmic strategy and the knowledge about the real possibilities of the spectrometer.

The accuracy of the temperature measurement under lab conditions was found to $\pm 1^{\circ} \mathrm{C}$.

The further progress of the project included the construction and installation of facilities to validate the method on a working industrial furnace and the online measurement of the temperature of the moving strip (Fig. 2).

Due to the harsh conditions of industrial environment, special cautions concerning thermal 


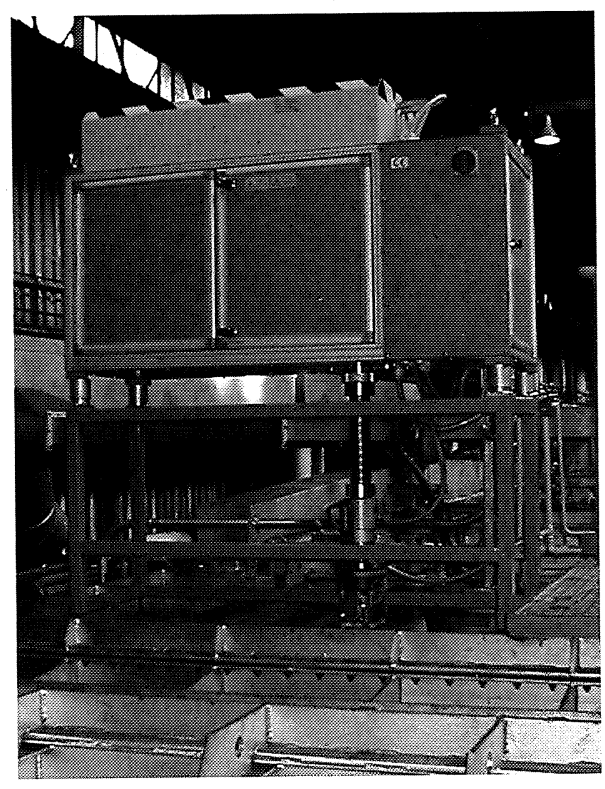

Figure 2. Cooled cabinet for FFTIR temperature measurement on the galvanising line.

Figura 2. Gabinete acondicionado para la medida de la temperatura con espectrómetro FFTIR sobre la línea de galvanización.

insulation and cooling had been taken into account.

It has been well established that the method is suitable for temperature measurements on-line and that the different agents being able to contravene interferometric measurements like low frequency mechanical vibrations of the furnace and particularly sheet vibrations or even jumps do not affect the spectrometer signal in such a way that the method fails.

Indeed when the sheet is running with speed of more than $100 \mathrm{~m} / \mathrm{min}$, the fluttering of the sheet causes some unpredictable jumping of the whole spectrum, so some software strategy for the accumulation of the spectra produces false results.

The key problem in the preparation of the new temperature measurement system was the fitting of non-linear algorithms for the real-time calculation of the true temperature from the measured specular data $^{\text {[28 and } 29]}$.

This problem was solved by matching the current measured spectra to certain reference spectres.

\subsection{Prediction of the mechanical properties of steel strips}

The measuring principle of the IMPOC system consists in the both sides local magnetisation of the moving strip by pulse magnetic field and the following measurement and averaging of the gradients of normal component of residual magnetic field strength (Fig. 3)

The averaged geometrical or arithmetical mean of the measured normal gradient of the magnetic field strength is correlated with the mechanical strip properties, the yield strength, the tensile strength and the elongation.

The statistical approach of this measurement system requires to collect results of parallel test of both the mechanical destructive tensile tests on particular steel grades with the same metallurgical routes and the magnetic residual field strength. To get a sufficient statistical dependence between these parameters a sampling of about 100 specimens is necessary.

The determination of the statistical correlation between the magnetic and the mechanical characteristics is based on the multiple linear regression function of the type: 123

$$
\mathrm{R}_{\mathrm{x}}=\mathrm{k}_{1}+\mathrm{k}_{2} \times \mathrm{H}_{\mathrm{i}}+\mathrm{k}_{3} \mathrm{XD}+\mathrm{k}_{4} \times \mathrm{V}_{\text {total }}
$$

with $\mathrm{R}_{\mathrm{x}}-$ mechanical properties $\left(\mathrm{R}_{\mathrm{m}}, \mathrm{R}_{\mathrm{p} 0,2}\right.$, $\mathrm{R}_{\mathrm{el}}, \mathrm{R}_{\mathrm{eh}}, \mathrm{A}$ )

$\mathrm{K}_{\mathrm{x}}-$ regression coefficient

$\mathrm{Hi}$ - value of the magnetic field strength gradient

D - strip thickness

$\mathrm{V}_{\text {total }}$ - total degree of skin pass deformation.

The technical data of the IMPOC system (table I) permit its application on low and medium speed, but also, after certain technical adaptation on high speed strip processing lines ${ }^{[9]}$.

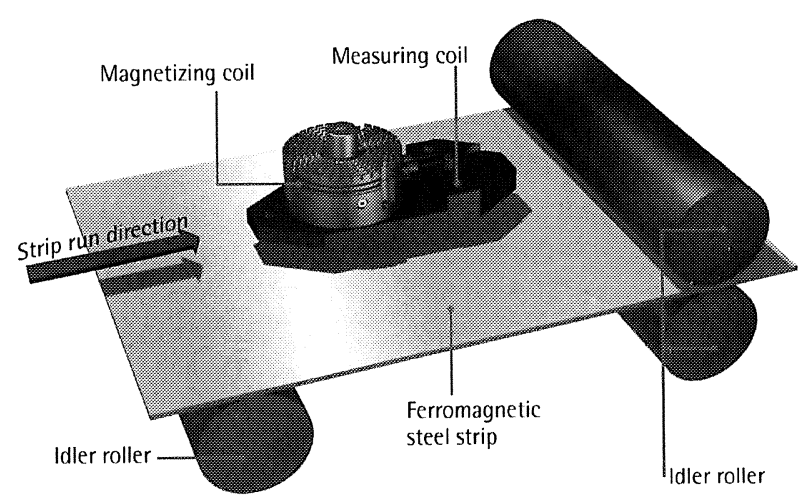

Figure 3. Typycal INPOC arrangement for measurement of residual magnetization.

Figura 3. Disposición típica INPOC, para la medida del magnetismo residual. 
On-line measurement of mechanical, optical properties and rough-ness parameters

H. HARTMAN, A. CASAJUS AND U. RICHTER

Table I. Strip parameters amd error range

Tabla I. Parámetros de la chapa y rango de error

Strip thickness

Strip width

Strip speed

Measuring error of the gradient of the remaining magnetism

Measuring error due to pass line variations up to $5 \mathrm{~m}$

power consumption
$0,15-12 \mathrm{~mm}$

$\min 500 \mathrm{~mm}$

$0,1-5 \mathrm{~m} / \mathrm{s}$

$<5 \%$

$<2 \%$

$\max 1,5 \mathrm{KVA}$

\subsection{Continuous roughness measurement}

The SORM3 + roughness measurement device consists of a measurement head with 20 lens/ photo elements which are arranged in this way that they set up a light balance in vertex (Fig. 4).

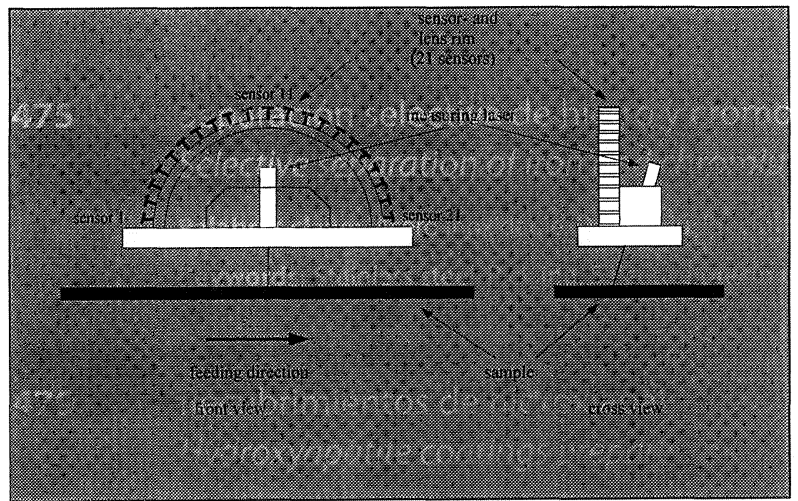

Figure 4. Basic sketch of SORM 3.

Figura 4. Esquema básico de SORM 3.
The measuring laser is a red laser $(660 \mathrm{~nm}, 22$ $\mathrm{mW}$ ) with a spot diameter of $6 \mathrm{~mm}$ laser measuring gap $50 \mathrm{~mm}$.

Some features of the SORM3+ to be emphasized on are the separation of the measuring process inside head and data processing outside the measuring head, the reduced laser spot diameter, which makes it possible to distinguish the roughness effect and the albedo in the scattered light, and the individual control of each sensor.

The measuring principle includes the pre-processing of the raw data by determination of the scattering light density, the follow up calculation of the surface height gauge and, after filtering (cut-off $2, \mathrm{~m} \mu \mathrm{m}$ ), of the surface roughness profile itself.

A record of a raw profile (blue line) and the calculated roughness profile of the surface (red line) are pictured in figure 5.

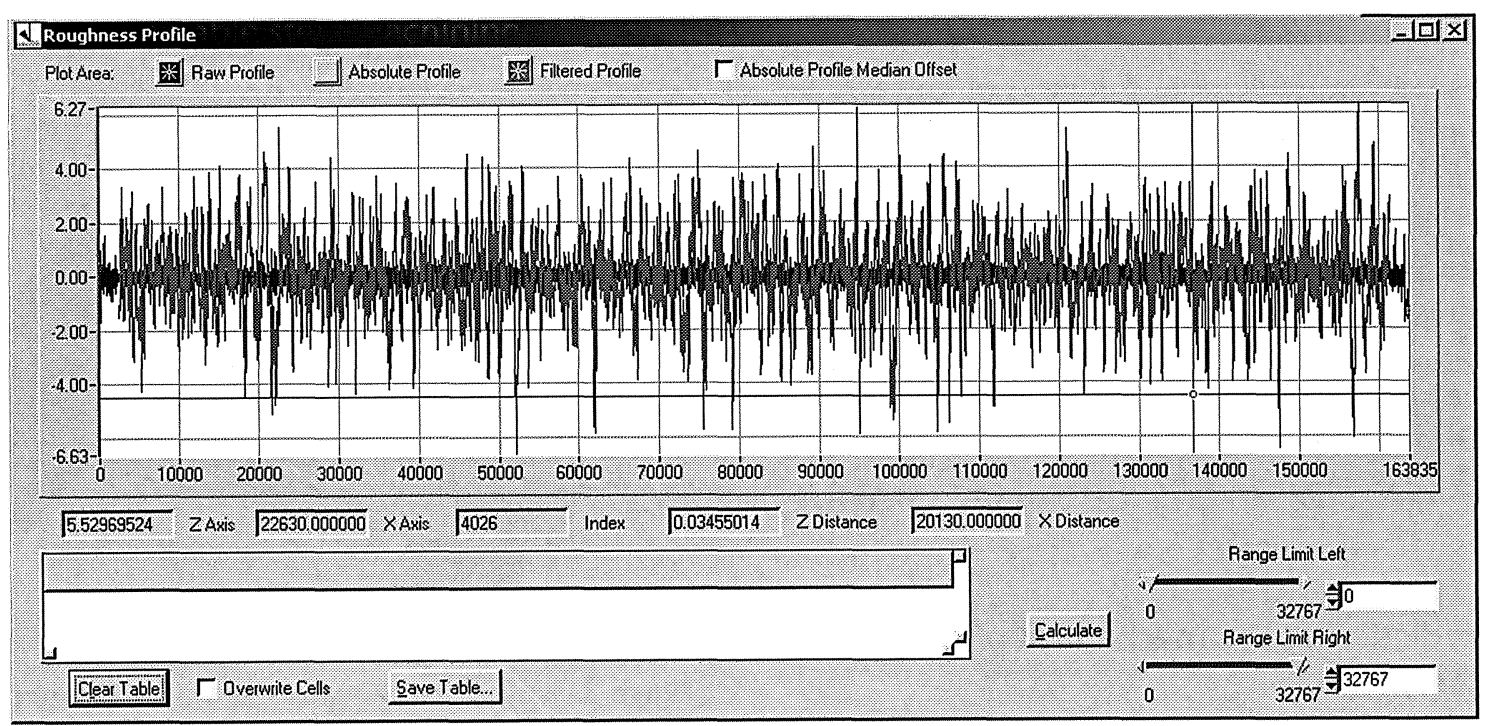

Figure 5. Raw profile and calculated roughness profile.

Figura 5. Perfiles en bruto y perfiles de rugosidad, calculados. 
The performance of the measuring device is shown in the following table II.

\section{RESULTS}

\subsection{Measurement of the true strip temperature}

The current spectra are modified as well as by the so-called response function of the instrument as by emissivity of the sample. Figure 6 shows the response function of the spectrometer for the used distance between the spectrometer and the sheet of $2.30 \mathrm{~m}$. The measured spectra must be corrected by the response function to get a Planck similar profile (blue curve), which is fitted by a Planck profile (red), whose least square fit is related to the temperature of the sample (Fig. 7).

If the emissivity coefficient (yellow) curve is constant, there is no shift of the Planck profile inducing a temperature uncertainty. Therefore, only the region of the spectrum where the emissivity is constant is used to fit the Planck profile leading to a temperature value being independent of the value of the emissivity coefficient.

Table II. Measurement parameters

Tabla II. Parámetros de medida

\begin{tabular}{ll}
\hline strip speed & $\max 1800 \mathrm{~m} / \mathrm{min}$ \\
measuring cycle & $1 \mathrm{~Hz}$ \\
$\begin{array}{l}\text { measuring length } \\
\text { scan distance }\end{array}$ & $\max 300 \mathrm{~mm}$ \\
measuring range & $5 \mu \mathrm{m}$ \\
$\mathrm{Ra}$ & \\
$\mathrm{RPC}$ & $0,1-2,5 \mu \mathrm{m}$ \\
\hline
\end{tabular}

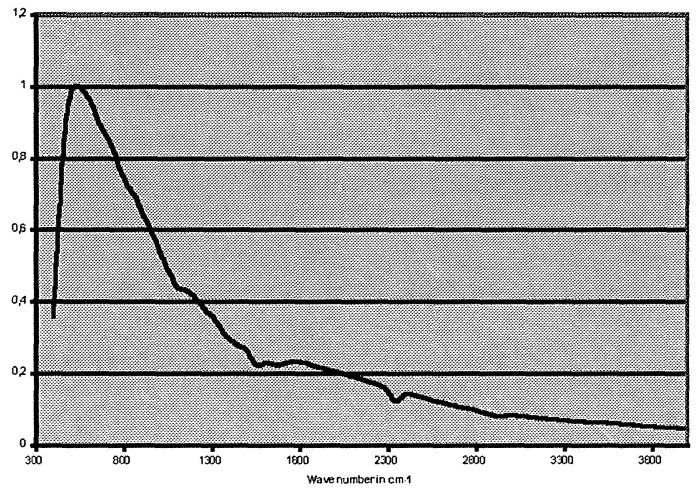

Figure 6. Response function profile.

Figura 6. Perfil de la función de respuesta.

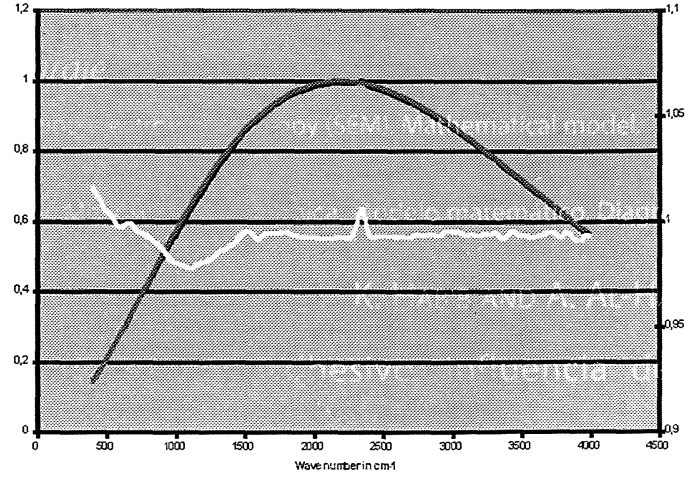

Figure 7. Matching of spectra by Planck.

Figura 7. Espectros emparejados con Planck.

\subsection{Prediction of the mechanical properties of steel strips}

The first IMPOK system was installed in 1997 at Galvanizing line 1, the second in 1999 at galvanizing line 2 at EKO Stahl. Both systems are embedded in the process control system of the plants that allow the analysis and follow-up of the technological process impact on the mechanical properties of the strip over the length (Fig. 8).

The mechanical properties of the today's common LC-, ELC- und ULC- steel grades and micro alloyed C-Mn-steels can be predicted by IMPOK-application (table) within small tolerances. The predicted accuracy of the mechanical properties is $\pm 5 \%$ and $\pm 10 \%$ for the tensile strength and the yield strength accordingly.

This enables us to reduce the efforts for mechanical destructive testing of the material and to avoid the associated costs. More important are the benefits for the process optimisation. The application of the IMPOK systems allows to increase the line speed up to the limit of the recrystallisation time in the annealing furnace and to optimise the cropping losses due to the unstable process conditions on the strip ends in the downstream process stages. Using IMPOK system it becomes possible to reveal small transition strip sections with insufficient, normally coarse grain metallic structure ${ }^{[1]}$.

\subsection{Continuous roughness measurement}

The roughness measurement system is in use for only some month used at the HDG line of EKO Stahl. One of the first results during the commissioning period is shown in figure 9. In this 


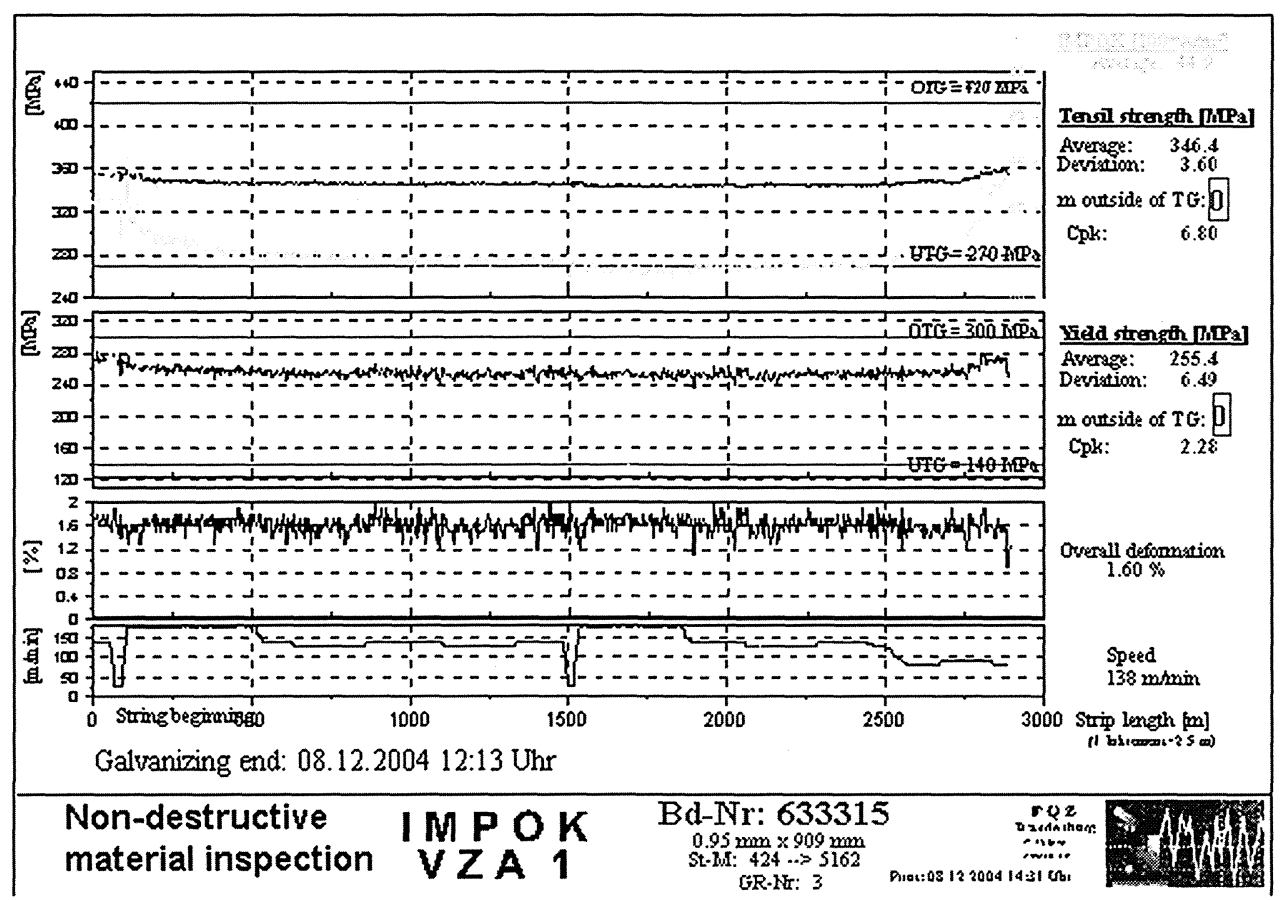

Figure 8. Typical plot of INPOC measurement.

Figura 8. Representación típica de una medida INPOC.

\section{Comparison: SORM3plus - stylus tip measurement}

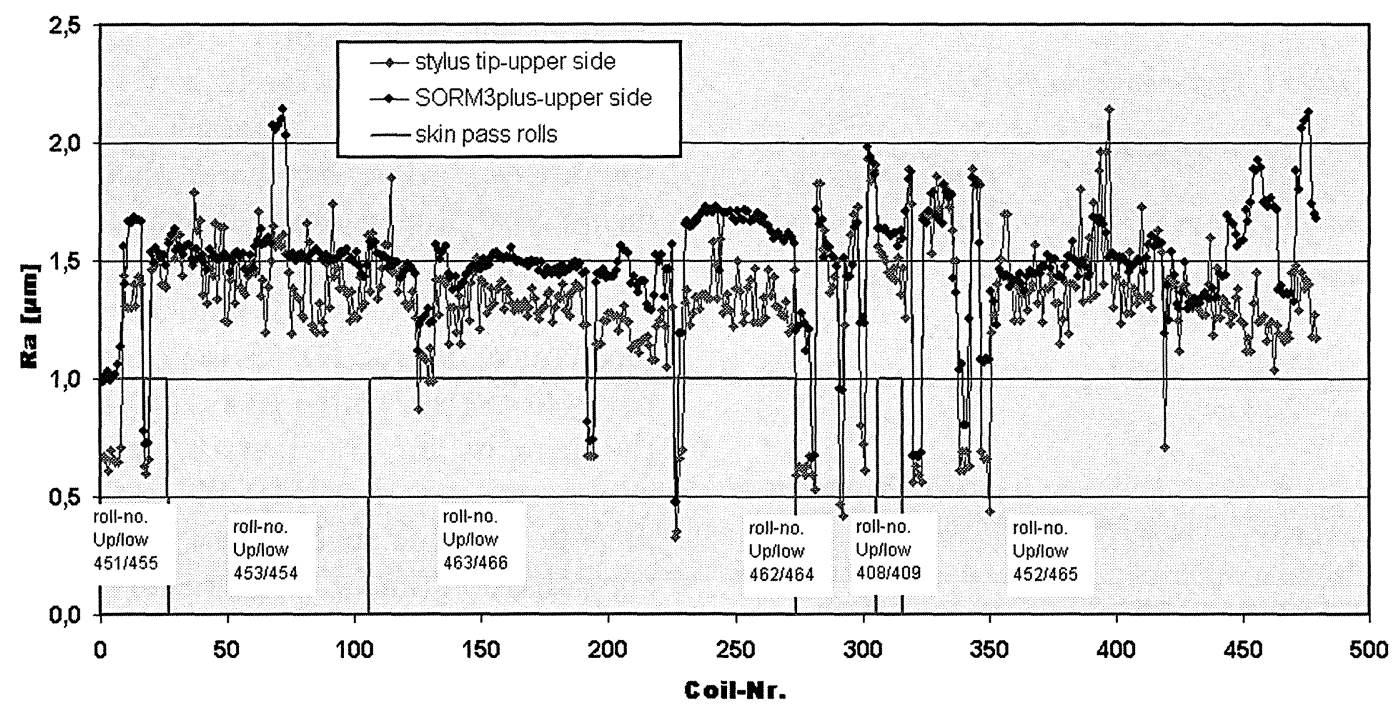

Figure 9. Comparison of the online SORM3plus roughness measurement system with a stylus tip measurement system.

Figura 9. Comparación del sistema de medida de rugosidad en línea, SORM 3 con un sistema de medida con punta de aguja.

figure the measured roughness is compared with the online measurement system and the stylus tip measurement. It can be seen a good agreement between the different measurement systems.
In figure 10 the influence of the specific roll force on the strip roughness is shown. The correlation between the roll force and the strip roughness is in good agreement with the expected 


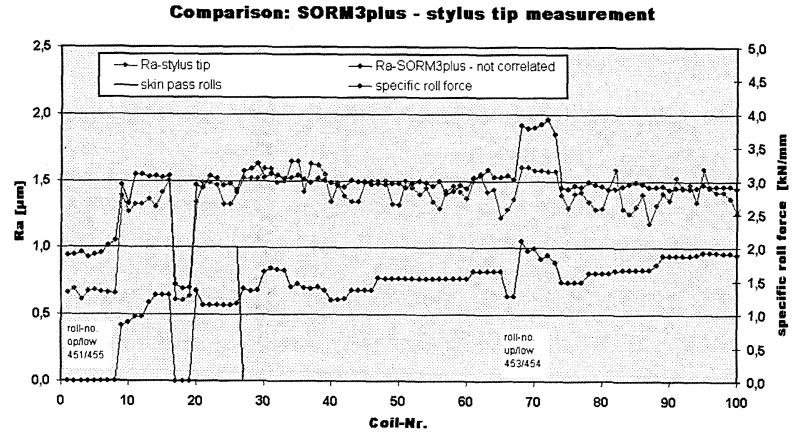

Figure 10. Interaction between the measured surface roughness and the specific roll Force.

Figura 10. Relación entre la rugosidad medida en la superficie y la fuerza específica de laminación.

technological process behaviour. Without skin pass deformation (arrow 1) the strip roughness is low. After change of the skin pass rolls (arrow 2) the increase of the rolling force results in a higher roughness.

The results of the first experimental approval of the measurement system could reveal a good agreement between the technological effect of the deformation parameter and the appropriated change of the roughness values.

\section{DISCUSSION}

\subsection{Measurement of the true strip temperature}

Pyrometric measurement of temperature of radiating surfaces suffers of well-known weaknesses. The broad aperture of the instrument makes the superposition of direct incoming radiation from the sheet as well as those from the furnace wall upon specular reflection on the sheet unavoidable.

Interferometers have a drastic tight aperture due to the very small spatial coherence of the interfering radiations, so only radiation close to the gauge axis comes to interference.

Measuring the maximum of the thermal profile, which reflects the value of the temperature, the absolute value of the emissivity becomes insignificant.

Indeed the slope of the emissivity over the spectrum range shifts also the temperature profile.

It is overcome by using suitable reference spectra and/or using the spectral range, where the emissivity is constant.

The proposed temperature measurement seems to be a method suitable to solve an old really unpleasing and fundamental problem of correct temperature measurement of radiating surfaces.

\subsection{Prediction of the mechanical properties of steel strips}

Despite the positive industrial application at EKO Stahl, which can be underlined by the commissioning of this measurement device in the pickling line for control the mechanical properties of hot rolled strip in this year, the technical development of the IMPOK-system has to be continued. The coming up activities for fitting the today's IMPOPK system are directed on the improvement of the statistical determination between the magnetic and mechanical properties by including additional magnetic parameters in the correlation analysis but also on the minimization of the dimension of the measurement device. Another direction for extension the usability of the IMPOK family is to adapt it to the measurement of texture depended properties and prediction of the formability ${ }^{[30}$ and 31$]$.

\subsection{Continuous roughness measurement}

By using a correlation analysis the optic measured values can be adjusted to the stylus tip values (Fig. 11). The optical measured values differ strongly from the stylus tip measurement. In this figure the values are correlated by a regression analysis. The certainty is nearly $57 \%$.

The regression formula can be integrated in the online calculation of $\mathrm{Ra}$ and RPc and the controller of the galvanizing line get values with a good agreement to the stylus tip measurements.

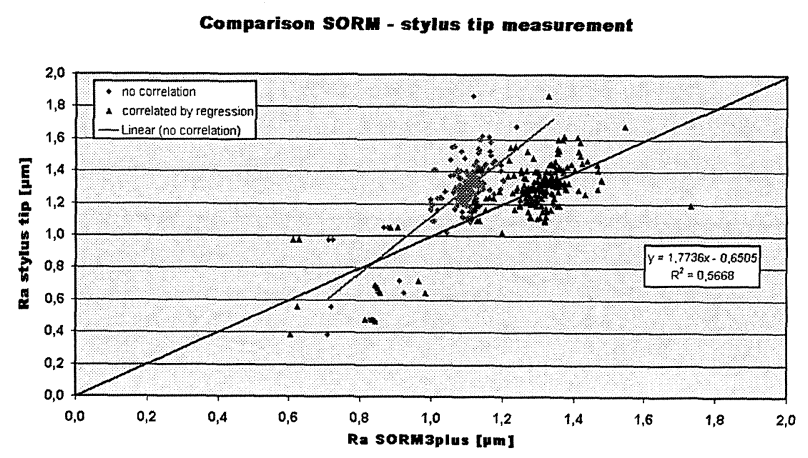

Figure 11. Adjustment of SORM3plus measured values to at the stylus tip values by a linear regression analysis.

Figura 11. Ajuste de los valores de las medidas SORM3plus con las medidas mecánicas con punta de aguja, por medio del análisis de regresión lineal. 


\section{CONCLUSIONS}

On-line measurements represent the new trend of modern production lines. A very important target is to save destructive proof methods by wellestablished correlations between traditional destructive checks and new processes.

On the other hand a huge amount of dates are generated which cannot be handled by traditional approach. So the most part of the dates are simply stored for tracking the "worst case" back, without to have the chance to be used in the daily work.

Therefore the generation of kilo-tonnes of information needs new tools for the automatical analysis of such high volume output also in-time.

\section{REFERENCES}

[1] R. Geirhofer, L. BaA and G. HinteramsKogler, VDI Ber., 1806 (2003) 77-82.

[2] H.G. WEYEN, Tagungsband Werkstoffprüfung (2003) 158167.

[3] O. Deutscher And K. ARmbruster, 3. Stahl-Symposium Werkstoffe, Anwendung, Forschung, 2003 Düsseldorf, Tagungsbericht, 1-17.

[4] S. Wagner, Thesis 1996, 159 Seiten.

[5] T. NeudeCKer, U. Popp, R. SchifFeR AND U. ENGEL, UTF Science II/2001, 13-17.

[6] H. EtTwig, R. JuschKa, H. Kolz and H. StaubermanN Stahl Eisen 106 (1986) 1232.

[7] P. Hervé, L. Viellard ANd A. Morel, Rev. Metall. (1997), 795.

[8] M.B. Kaplinsky, J. Li, N.J. MCCaffrey, E.S. Hou and W.F. Kosonocky, Proc. SPIE, Vol. 2746, 1996, pp. 178 189.

[9] T. Fu, X. Cheng, X. FAn and J. Ding, Metrologia 41 (2004) 305-313.

[10] V. TANK, Thesis, TU Munich, 1998.
[11] P.R. GRIfFithS AND J.A. DE HASETH, Fourier Transform Infrared Spectroscopy Wiley, New York, 1986.

[12] S. Clausen, A. Morgenstjerne and O. Rathmann, Appl. Opt. 35 (1996)

[13] E. Lindermeier, P. Haschberger, V. TANK ANd H. Dietl, Appl. Opt. 31 (1992).

[14] A. Casajus, J.M. Powell, F. Muilwijk and J.L. ReNdUelEs-VigiL, Technical Steel Research, EuR 20463 EN, 2002.

[15] V.F. MATYUK, Institut für Abgewandte Physik, Minsk, 2001.

[16] H. HartmanN, Tagungsband zur 11. Sächsischen Fachtagung Umformtechnik, Freiberg, 2004.

[17] H. Hartmann, Proc. Internationalen wissenschaftlichtechnischen Konferenz, Moskau, 2004.

[18] V.F. MATYuK, S.A. GoncharenKo, H. HARTMANN AND H. ReICHELT, Defectoskopiya 5 (2003)19-60 (in Russian).

[19] M. Borsutzki, J.RoOs, W.ReIMCHEN AND E. SCHNEIDER, Stahl Eisen H. 12, (2000) 115-121.

[20] G. Dobmann, R. Kern And B. Wolter, Proc. $16^{\text {th }}$ WCNDT, Montreal, 2004.

[21] B. Heutling, W. Reimche, F.W.Bach, M. Stock, M. Stolzenberg AND S. Schulz, Proc. $16^{\text {th }}$ WCNDT, Montreal, 2004.

[22] O. Pawelski, W. RasP, W. Zwick, H. Nettelbeck and K. StEINHOFF, J. Mater. Process. Technol. 45 (1994) 215-222.

[23] F. Raharijaona, X. Roizard and J. von Stebut, Tribol. Int. 32 (1999) 59-67.

[24] T. Massart, B. Lejeune, D. Malaise and L. Broussard, Rev.Metall. 2003, 317-323

[25] DMO, Windis, www.dmo.be,

[26] EMG, SORM3plus, www.emg-automatisation.com

[27] MESACON, www.ldv-systeme.de

[28] D.W. MARQUARDT, J. Soc. F. Industrial a. Applied Math., Vol. II, (1963) 431.

[29] K. Levennberg, Q. Appl. Math. 1944, 164.

[30] H. HartmanN, H. Reichelt, V.F. Matyuk, V.B. Kratirov AND GONCARENKO, Institut für Abgewandte Physik, Minsk, 2001.

[31] V. Matyuk, A. Osipov, M. Delendik, H. Hartmann and H. ReICHELT, Proc. $16^{\text {th }}$ WCNDT, Montreal, 2004. 